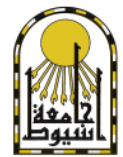

AUCES

\title{
ISOLATION AND CHARACTERIZATION OF RHAMNOLIPID (BIOSURFACTANT) FROM PETROLEUM CONTAMINATED SOIL
}

\author{
Abdurrahim A. Elouzi1, Rehab Bashir, Ryma Sandouk and Bassam \\ Elgammude
}

\author{
Department of pharmaceutical sciences, Faculty of pharmacy, Elfateh University, Tripoli-Libya
}

E-mail: abdurahim68@hotmail.com

\begin{abstract}
:
In the last decades, biosurfactants have attracted attention of many scientists because of their low toxicity, biodegradability and ecological acceptability. Nevertheless, their use is extremely limited due to the high cost when compared with chemical surfactants. In this study we have isolated bacteria from different environmental sources located in Sarris field (Zawia-Libya). The isolate was identified as Pseudomonas aeruginosa by comparing its 16S rDNA sequence with those available in The National Center for Biotechnology Information (NCBI) gene bank (accession number was AJ746 135). Using gel electrophoresis technique, the length of DNA was identified. The strain was selected for its ability to produce extra cellular products (biosurfactants) able to reduce surface tension and emulsify the kerosene. The production of rhamnolipid was carried out using a well-controlled one-liter laboratoryscale flask fermentor. In the same time, optimum concentration of substrate (glycerol) was investigated and phenol sulphuric acid test was conducted to measure the concentration of produced rhamnolipid. The identification tests such as specific growth rate $(\mu)$, protein measurement, emulsification activity and stability test were also studied. The results showed that the extracellular surface active agent produced by the indigenous strain $P$. aeruginosa was identified as Rhamnolipid, which is one of the most commonly used biosurfactants with the ability to reduce surface tension of water. The maximum concentration of rhamnolipid isolated using $1 \%$ glycerol which was $170 \mathrm{mg} / \mathrm{l}$. This biosurfactant had excellent emulsification index (E24) of $70 \%$ and stability of $67 \%$ comparable to or better than that from the conventional rhamnolipid which was $66 \%$ and $58 \%$ respectively.
\end{abstract}

\section{INTRODUCTION:}

Biosurfactants are a chemically diverse group of surface-active molecules produced by various groups of microorganisms that may belong to yeast, bacteria, filamentous fungi, plants and animals ${ }^{[1,2]}$. Surfactants manufactured by the chemical industry pose environmental problems because of their toxicity and resistance to degradation ${ }^{[3]}$.
There is currently interest in replacing these chemical surfactants with surfactants of biological origin $^{[3-5]}$.

In the last decades, these biosurfactants have attracted attention of many scientists because of their potential advantages over their synthetic relatives. these advantages include low toxicity (environmentally friendly), high biodegradability and biodegradable, high selectivity and specific activity, availability of it's raw material where biosurfactant can be produced from cheap raw materials, which are 
available in large quantity ${ }^{[4-6,17]}$. Biosurfactants can also be produced from industrial wastes and by-products and this is of particular interest for bulk production (e.g. for use in petroleumrelated technologies). Also it is possible to produce biosurfactants in situ at contaminated $\operatorname{sites}^{[6,7,17]}$.

Biosurfactants are categorized mainly by their chemical composition and their microbial $\operatorname{origin}^{[7,8]}$. In general, their structure includes a hydrophilic moiety consisting of amino acids or peptides anions or cations; mono-, di-, or polysaccharides; and a hydrophobic moiety consisting of unsaturated, saturated, or fatty acid $^{[1,2,6]}$. Desai and Banta (1997) have been classified the biosurfactant into Lipopeptides and lipoproteins, glycolipids, Polymeric, fatty acids, phospholipid and neutral lipids and particulate biosurfactant ${ }^{[9]}$.
Glycolipids biosurfactants are the most promising, due to high productivity from renewable resources and versatile biochemical properties. These carbohydrates biosurfactant normally present in combination with longchain aliphatic acids or hydroxyaliphatic acids $^{[10,11]}$. Among the glycolipids, the best known are rhamnolipids, trehalolipids, and sophorolipids $^{[16]}$.

Rhamnolipids are a thermo-tolerant biosurfactant produced by Pseudomonas aeruginosa. The term is indicative of the fact that these lipids contain one or two rhamnose units, linked glycosidically to one or two molecules of $\beta$-hydroxydecanoic acid. Thus, the monorhamnolipid from Pseudomonas aeruginosa grown on hydrocarbons is $2-0-\alpha-\mathrm{L}-$ rhamnopyranosyl - $\alpha$-L- 3- hydroxydecanoyl -3hydroxydecanoic acid ${ }^{[12-16]}$.

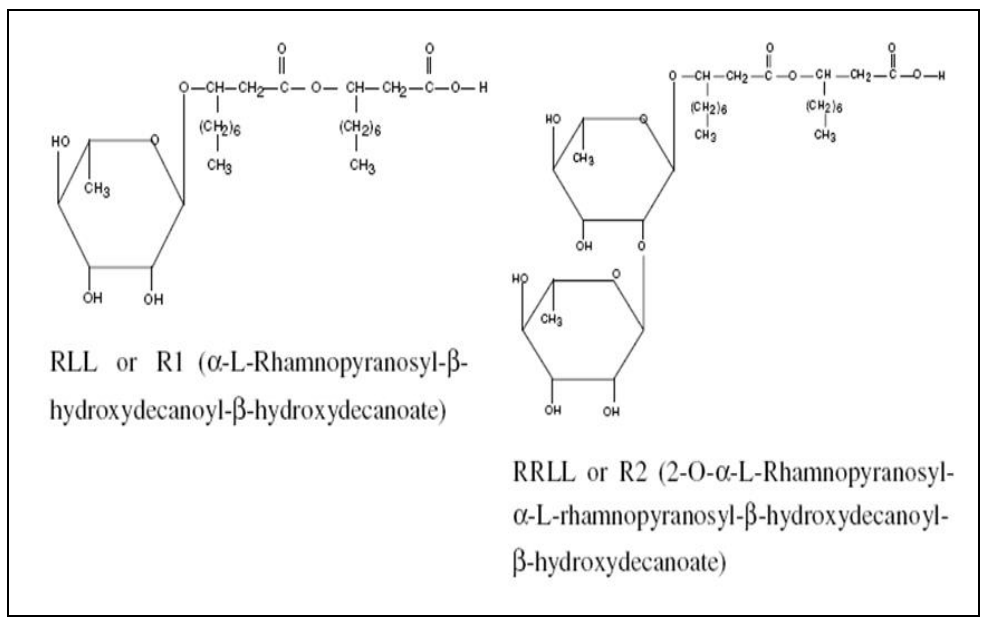

Figure (1): Structure of Rhamnolipids

Rhamnolipids have several potential industrial and environmental applications including the production of fine chemicals, the characterization of surfaces and surface coatings, as additives for environmental ${ }^{[19]}$. Also they can be efficiently used in handling industrial emulsions, biodegradation and detoxification of industrial effluents, control of oil spills, and in bioremediation of contaminated soil ${ }^{[20,23,28]}$. In agriculture; biosurfactants rhamnolipid have a role in plant pathogens elimination, in solubilizing hydrophobic 
compounds from contaminated soil, in decontamination of soil from pesticides and in metal contaminated soils remediation ${ }^{[21,22]}$. In food processing $\&$ additive; biosurfactants have been used as antioxidant agent, thickeners and viscosifiers in food products, anti-adhesive and food emulsifiers ${ }^{[19,24,25]}$. Pharmaceutically; antibiotic resistance is a serious and widespread problem which is due to several reasons. One reason that is particularly important for hydrophobic antibiotics is that cells do not take them up ${ }^{[26]}$ Rhamnolipids are one of the main biosurfactants, which tested for the uptake of hydrophobic antibiotics in vivo to enhance its activity $^{[26,27]}$.

\section{MATERIAL AND METHOD:}

1-Bacterial strains and growth
conditions:

The Pseudomonas aeruginosa used in this work was isolated from fouling environmental samples located near Sarris oil field near ZawiaLibya. The bacteria was cultured on R2A medium (Sigma, UK) that consists of: yeast extract $0.5 \mathrm{~g}$, proteose peptone $0.5 \mathrm{~g}$, casamino acids $0.5 \mathrm{~g}$, glucose $0.5 \mathrm{~g}$, soluble starch $(0.5 \mathrm{~g})$, sodium-pyruvate $(0.3 \mathrm{~g})$, dipotassium hydrogen orthophosphate $\left(\mathrm{K}_{2} \mathrm{HPO}_{4}, 0.3 \mathrm{~g}\right)$, magnesium sulfate $\left(\mathrm{MgSO}_{4} \cdot 7 \mathrm{H}_{2} \mathrm{O}, 0.05 \mathrm{~g}\right)$, distilled water $1,000 \mathrm{ml}$ (final pH 7.2).

\section{2-Characterization of Bacterial Strains:}

The characterization and identification of bacterial strains (Figure 2) were achieved according to standards for microbial identification in Bergey's manual of systematic bacteriology, on the morphology basis of the colony (shape and pigments), biochemical tests (oxidase and catalase tests) and microscopic examination (Gram-stain and motility) ${ }^{[29]}$.

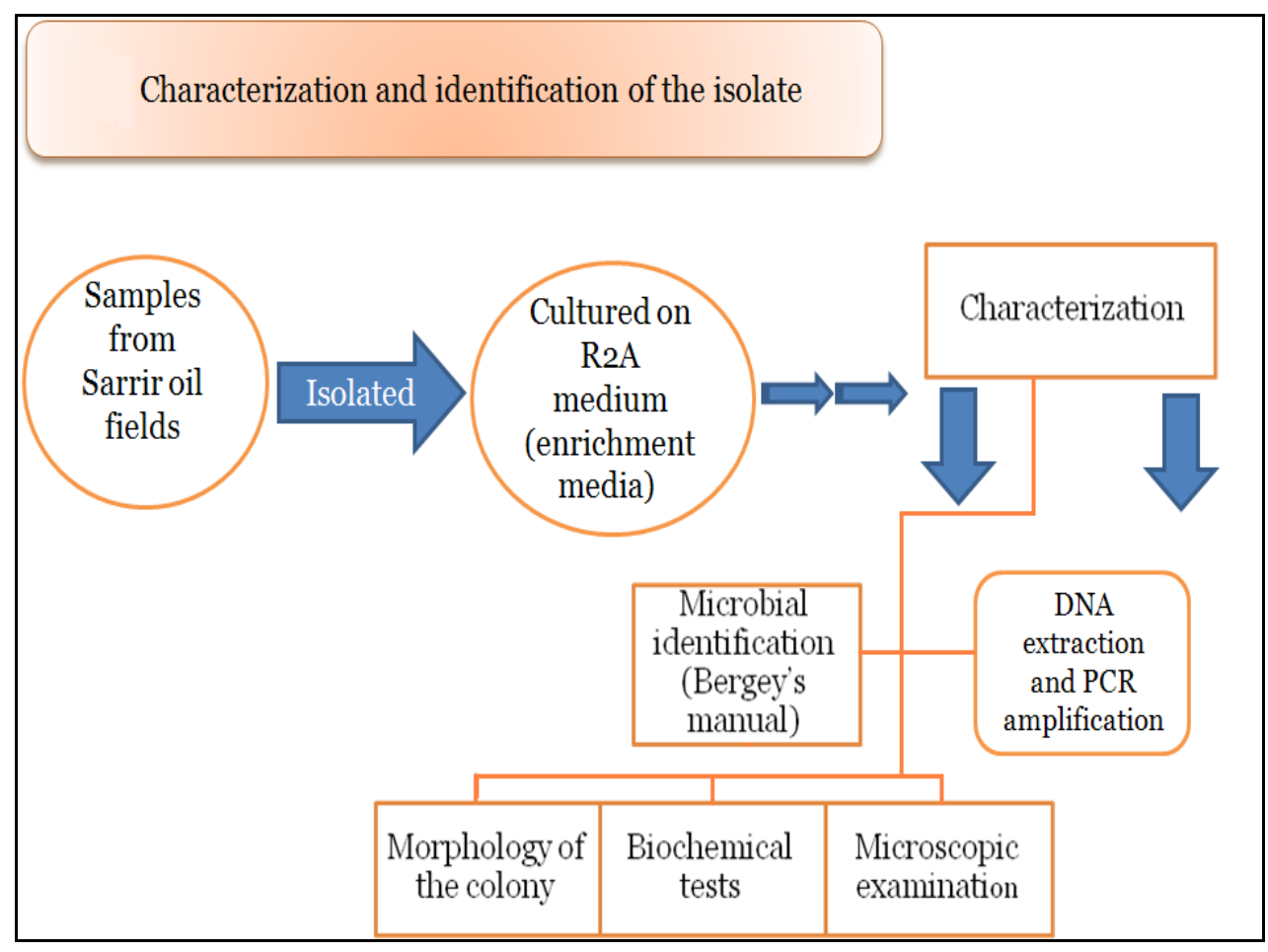


Figure (2): Schematic depiction the characterization and identification of isolated bacterial

3-DNA extraction from isolated strain and Polymerase Chain Reaction (PCR) amplification:

a-Nucleic acid extraction:

DNA was extracted from bacterial strains and purified by G-spin genomic DNA extraction kits (from INTRON biotechnology, mc), where silica membrane technology used for efficient purification of DNA. The bacterium-specific primers used to amplify 16S rRNA gene fragments were [27F primer (5-AGAGTTT GATCCTGGCTCAG-3')] and 1492R primer (5'-GGT TAC CTT GTT ACG ACT T-3')]; these primers were frequently used in molecular diversity studies because they result in a nearly full-length 16S rDNA product and were considered universal for the domain bacteria ${ }^{[30]}$.

\section{b-PCR and sequencing of the 16S rDNA:}

The 16S rRNA genes from bacterial strain was sequenced partially to ensure sequence identity for all of the strains used in this study and the strains represented in the Sanger Method -Dideoxynucleotide chain termination. Sequencing of the separated amplified product was done by the ABI 310 Genetic Analyzer with $50 \mathrm{~cm}$ long capillary (Department of Microbiology, Eotvos Lorand University of Science, Budapest). Data were collected and corresponding bases were called by using the ABI's Sequence Analysis software. Sequences were compared to GenBank sequences by using a standard nucleotide basic local alignment search tool (BLAST) $\operatorname{search}^{[31]}$.

\section{4-Growth measurements:}

The growth rate of Pseudomonas aeruginosa AJ 746135 was determined by measuring culture turbidity and total protein. The growth rate on glycerol was monitored in Mineral Salt
Medium (MSM). The concentration of glycerol 1\% was evaluated through measuring the Optical density (OD) of growing cultures (the specific growth rate $(\mu)$ at $600 \mathrm{~nm}\left(\mathrm{OD}_{600}\right)$ by using a spectrophotometer (Aqua Quest, model: CE 4004).

The Growth was carried out in $250 \mathrm{ml}$ flasks filled with $50 \mathrm{ml}$ mineral salt medium at $150 \mathrm{rpm}$ and incubated at $30^{\circ} \mathrm{C}$ for 17 hours, then one $\mathrm{ml}$ of the sample was collected every two hours, this process was continued for three consecutive days.

\section{5-Total protein measurement:}

Total protein can be quantified using a modified Lowry Kit, Peterson's Modification of Micro-Lowry Method for protein determination (Sigma-Alidrich, UK P5656,) with bovine serum albumin (BSA) as a standard.

This colorimetric method based on the Folin reaction. The blue colour appearing in the assay was due to the reaction of protein with copper ion in alkaline solution. The reduction of the phosphomolybdate-phosphotungstic acid in the Folin reagent by the aromatic amino acids in the treated protein was the reason therefore. This method was useful for proteins that were already in solution or that were soluble in dilute alkali (Protocol of Modified Lowry Kit). Total protein was measured at $750 \mathrm{~nm}$ and the protein concentration was determined in relation to bovine serum albumin (BSA) which was used as a standard ${ }^{[32]}$.

The calibration is made by solutions of BSA in water with concentrations in the range from 0 to $60 \mathrm{mg} / \mathrm{l}$. The assay was carried out as the following; prepared standard solutions of BSA in the concentration range of 0 to $60 \mathrm{mg} / \mathrm{l}$. Add $0.5 \mathrm{ml}$ of Lowry reagent to $0.5 \mathrm{ml}$ of each sample which has been pipetted in test tubes. 
Stirred carefully (avoid foaming) and the mixture was incubated for 20 minutes at room temperature. Then $0.25 \mathrm{ml}$ of Folin-Ciocalteu phenol reagent was added and stirred gently. The mixture was incubated for 30 minutes at room temperature in the dark. Measure the absorbance at $750 \mathrm{~nm}$ of each sample ${ }^{[32]}$.

\section{6-Fermentations:}

The production of rhamnolipids was studied during a seven-day fermentation period in flasks under agitation with the initial seeding material standardized in a culture medium, maintained at a temperature of $30^{\circ} \mathrm{C}$ and stirred in a rotary shaker at $150 \mathrm{rpm} .1 \%$ of glycerol was used as a carbon source.

The culture medium that used to grow pseudomonas aeruginosa AJ746135 strain was a mineral salt medium (MSM) supplemented with $1.5 \mathrm{~g} / \mathrm{l} \mathrm{NaNO}, 4.65 \mathrm{~g} / / \mathrm{K}_{2} \mathrm{HPO}_{4}, 1.5 \mathrm{~g} / 1 \mathrm{NaH}_{2} \mathrm{PO}_{4}$, $0.2 \mathrm{~g} / \mathrm{l} \mathrm{MgSO}_{4} \cdot 7 \mathrm{H}_{2} \mathrm{O}, 2 \mathrm{ml}$ trace elements and $1 \%$ of glycerol. The $\mathrm{NaNO}_{3}$ was used instead of $\mathrm{NH}_{4} \mathrm{SO}_{4}$ because the former was employed as nitrogen source and that would result in a higher production of the rhamnolipid ${ }^{[33]}$.

For liquid fermentation, a loopful of Pseudomonas aeruginosa AJ746135 cells taken from the seed culture was added into a $250 \mathrm{ml}$ Erlenmeyer flask containing $50 \mathrm{ml}$ MSM and grown in a rotary shaker set at $30^{\circ} \mathrm{C}$ and 150 rpm.

After growing for $24 \mathrm{~h}$, the culture (inoculums) was inoculated into $500 \mathrm{ml}$ liquid medium and was cultivated at $30^{\circ} \mathrm{C}$ and 150 rpm for 7 days. To collect rhamnolipid from fermentation culture, the supernatant of collected cultures was first centrifuged at $\mathbf{1 3 0 0 0}$ rpm for 30 minutes to remove biomass and the supernatant was tested by using phenol-sulfuric acid method to determine the concentration of biosurfactants, after being sterilized in the autoclave.

\section{7-Biosurfactant detection:}

To detect the presence of the biosurfactant (Figure 3), the following tests were conducted:

\section{a-The quantification of rhamnolipids:}

The quantification of rhamnolipids expressed in rhamnose $\left(\mathrm{mgl}^{-1}\right)$ was measured in the culture medium, using the phenol sulfuric $\operatorname{acid~method~}^{[35]}$.

In phenol-sulfuric acid assay, the glucose was used as a standard. Other standards such as "ribose" could be used but the results were not comparable with those obtained by using the glucose calibration standard. For phenolsulfuric acid assay, at first, the solutions for the calibration had to be prepared by dissolving glucose in deionized water in concentrations from 20 to $400 \mathrm{mg} / \mathrm{l}$ starting with $0 \mathrm{mg} / \mathrm{l}$. From each solution $0.5 \mathrm{ml}$ was poured in a covered test tube. To which $0.5 \mathrm{ml}$ of each sample or diluted sample was added. Then quickly $0.5 \mathrm{ml}$ of $5 \%$ phenol was added, and the solution was mixed with the Vortex and $2.5 \mathrm{ml}$ of concentrated sulphuric was added and vortex again. The mixture was incubated for 5 minutes at $30^{\circ} \mathrm{C}$, then for 10 minutes at room temperature to cool down. The absorbance of each sample was measured at $490 \mathrm{~nm}$ (spectrophotometer, Perkin-Elmer, UK).

\section{b-Measuring Emulsification Activity and Stability of Biosurfactants:}

Emulsification activities and stability of biosurfactants were measured using the method of Cooper and Goldenberg ${ }^{[34]}$. In this method, 2 ml of biosurfactant solution was diluted with 2 ml of substrate (kerosene) in a screw cap test tube. The mixture was vigorously shaken in a vortex mixer at high speed for 2 minutes 
(Vortex top mix, sigma- UK). The emulsion stability was determined after 24 hours and the activity was determined after an hour. The equation used to determine the emulsion index E24 (\%) was as follows:

$E 24(\%)=$ The height of emulsion layer/ (the height of total solution $\times 100$ )

\section{c-Comparison with commercial} biosurfactants:

The emulsification activity and stability of commercial biosurfactants were measured. Both surfactants were diluted to $1 \mathrm{~g} / \mathrm{l}$ by weight and were analyzed using the method of Cooper and Goldenberg and kerosene as substrate ${ }^{[34]}$.

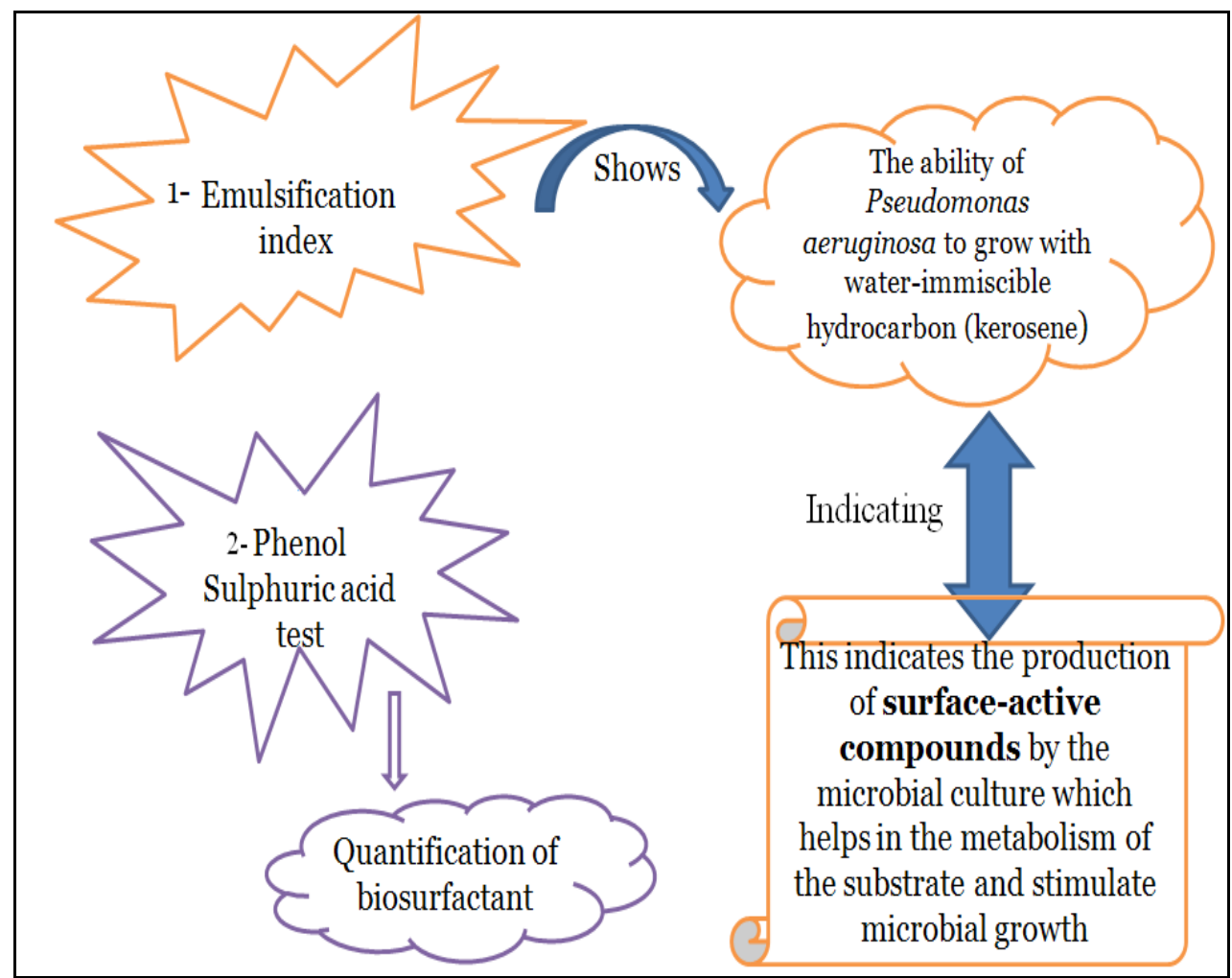

Figure (3): Schematic illustrates the methods that used to detect on Rhamnolipid (biosurfactant)

\section{RESULTS AND DISCUSSION:}

\section{1-Characterization and identification of the isolate:}

The characteristic of the isolate showed an aerobic, gram-negative, and motile, rods shaped, producing green pigments bacteria (Figure 4) and the biochemical tests was carried out according to Bergey's manual ${ }^{[29]}$, clearly seemed to be Pseudomonas species.

Bacterial strain was also tested by $16 \mathrm{~S}$ rDNA polymerase chain reaction techniques (PCR) as described previously. The extracted DNA was checked by Agarose gel electrophoresis to determine the amount and purity of DNA (Figure 5). 


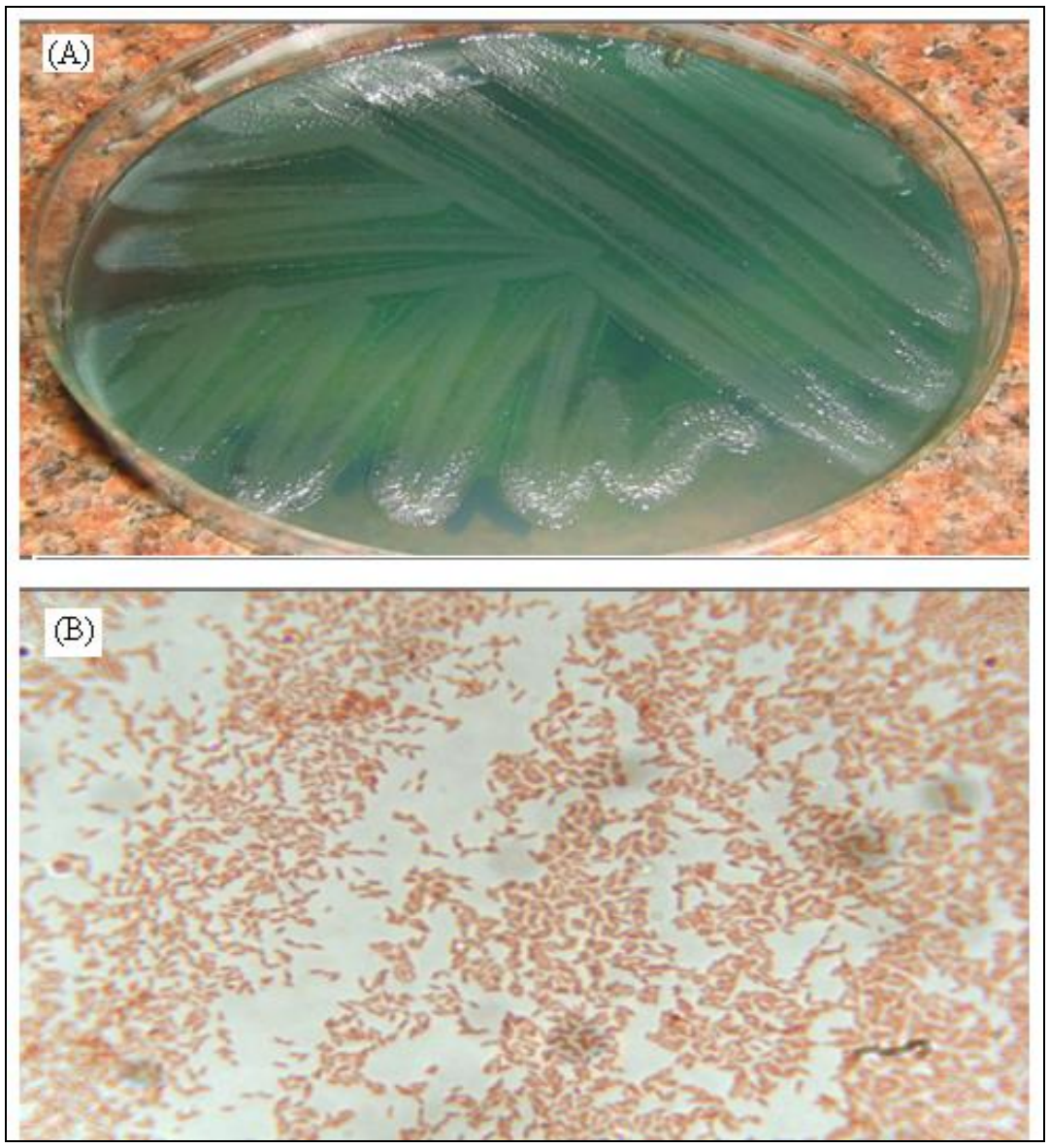

Figure (4): The colony morphology of P. aeruginosa on (A) Pseudomonas agar and (B) gram stain

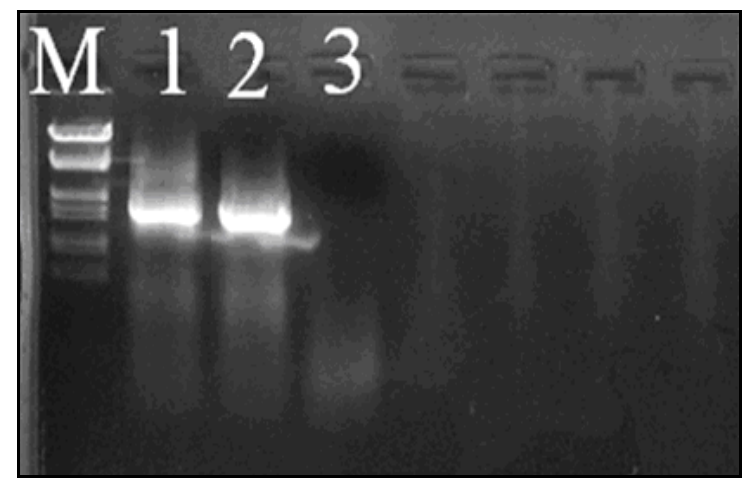

Figure (5): PCR amplification of total DNA extracted from pure culture. The agarose gel electrophoresis indicated the presence of bacterial DNA as the following: lane M represents the DNA ladder (Marker); lane1 represents isolated Pseudomonas aeruginosa; lane 2 represents the positive control and lane 3 represents the negative control where only background staining was seen. The electrophoresis was used in order to establish the purity and integrity of the isolated bacteria. 
The results of PCR amplification of the $\mathbf{5 0 0}$ BP region of the 16S rRNA gene showed that bacteria indentified as Pseudomonas aeruginosa with following sequencing:

(GTCGAGCGGATGAAGGGAGCTTGCTCC TGGATTCAGCGCGGACGGGTGAGTAATG CCTAGGAATCTGCCTGGTAGTGGGGATA ACGTCCGGAAACGGGCGCTAATACCGCA TACGTCCTGAGGAGAAAGTGGGGGATCT TCGGACCTCCGCTATCAGATGAGCCTAG GTCGGATTAGCTAGTTGGTGGGGTAAAG GCCTACAAGGCGACGATCCGTAACTGGT CTGAGAGGATGATCAGTCACACTGGAAC TGAGACACGGTCCAGACTCCTACGGGAG GCAGCAGTGGGGAATATTGGACAATGGG CGAAAGCCTGATCCAGCCATGCCGCGTG TGTGAAGAAGGTCTTCGGATTGTAAAGC ACTTTAAGTTGGGAGGAAGGGCAGTAAG TTAATACCTTGCTGTTTTGAC) and Sequences obtained in this study have been deposited in GenBank under accession numbers AJ746135 with $100 \%$ identity (Figure 5).

\section{2-The Growth measurement:}

The specific growth rates $(\mu)$ of Pseudomonas aeruginosa AJ746 135 on glycerol were determined by linear relationship for optical density (OD) against time. Figure 6 illustrated the growth curves of $P$. aeruginosa AJ746 135 cultivated in mineral salts medium containing $1 \%$ concentration of glycerol as source of carbon. The growth curve constancy was observed after $16 \mathrm{hrs}$, where glycerol had been consumed.

The results showed that $P$. aeruginosa AJ746135 growth curve (Figure 6), using 1\% glycerol, yielded a specific growth rate and total protein of $0.659 \mathrm{hr}^{-1}$ and $170 \mu \mathrm{g} \mathrm{ml} \mathrm{ml}^{-1}$, respectively (Table 1 ).

\section{3-Biosurfactant detection:}

The emulsification index results showed the ability of P. aeruginosa AJ746 135 to grow with water-immiscible hydrocarbon (kerosene). This indicated the production of surface-active compounds by the microbial culture which helped in the metabolism of the substrate and stimulated microbial growth.

As for the quantification of the biosurfactant (rhamnolipid), the results of phenol sulfuric acid assay showed that the supernatant contains $114 \mu \mathrm{g} \mathrm{ml}^{-1}$ of biosurfactant rhamnolipid (coded as Lbio) while commercial biosurfactants (coded as Cbio, which kindly obtained from Ulster university, UK) was diluted to 100-300 $\mu \mathrm{g} \mathrm{ml}^{-1}$.

Figure (7) showed the stability of Lbio at different concentration and incubation time and the results concluded that the emulsification index of $1 \%$ biosurfactant was significantly high and also more stable when compared with other Lbio concentration. As for the use of the biosurfactant in enhancing the solubility of continent hydrocarbon, it was found that the low concentration was the most recommended ${ }^{[36,37]}$. Therefore a concentration of $1 \%$ was used thereafter for comparison between commercial and laboratory produced biosurfactant.

Figures (8\&9) explained the emulsification index of $P$. aeruginosa AJ746135 biosurfactant (Lbio) comparing with commercial biosurfactants (Cbio), where the value of emulsification index of Lbio was found to be greater than the values of Cbio which was $70 \%$ while Cbio was only $66.33 \%$, using Kerosene as the hydrophobic compound. 
The stability of laboratory produced biosurfactant was conducted during various incubation time and the results showed that after 24 hrs, the Lbio showed a higher stability than Cbio where the values were $67 \%$ for Lbio and $58 \%$ for Cbio (Figure 9).

Table (1): Below shows the doubling time and maximum growth rate values Pseudomonas aeruginosa.

\begin{tabular}{|c|c|c|c||}
\hline \hline Concentrations & $\mu$ & Dt & Total protein (= biomass) \\
\hline $1 \%$ & $0.659 \mathrm{hr}^{-1}$ & 1.063 & $170 \mu \mathrm{g} / \mathrm{ml}$ \\
\hline
\end{tabular}

*dt-doubling time, * $\mu$-specific growth rate.

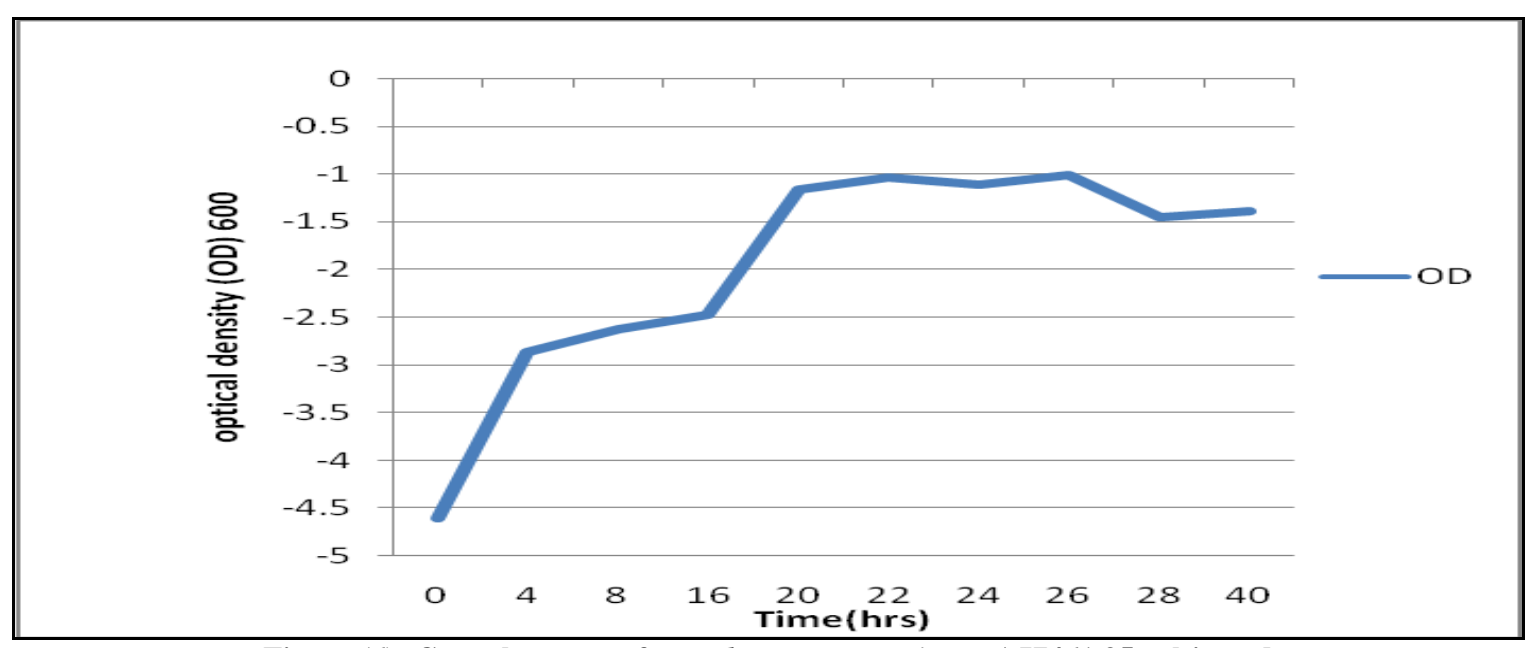

Figure (6) :Growth curves of Pseudomonas aeruginosa AJ7461 35 cultivated

in mineral salt medium containing $(\mathbf{1 \%})$ concentration of glycerol as source of carbon

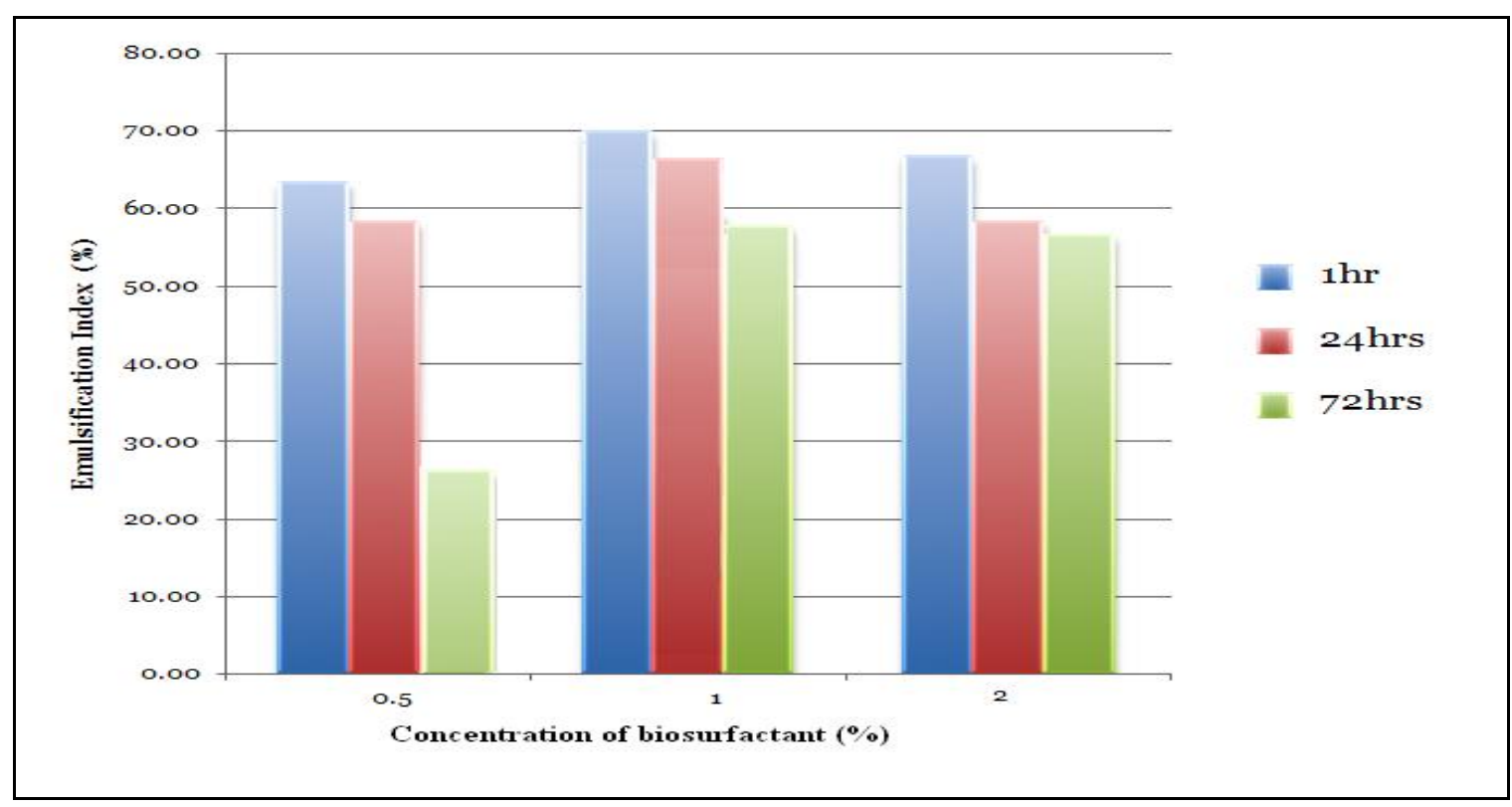

Figure (7): The stability of laboratory produced biosurfactant $\left(L_{b i o}\right)$ at different concentrations and after various incubation time, indicated by its effect on Kerosene as the hydrophobic compound 


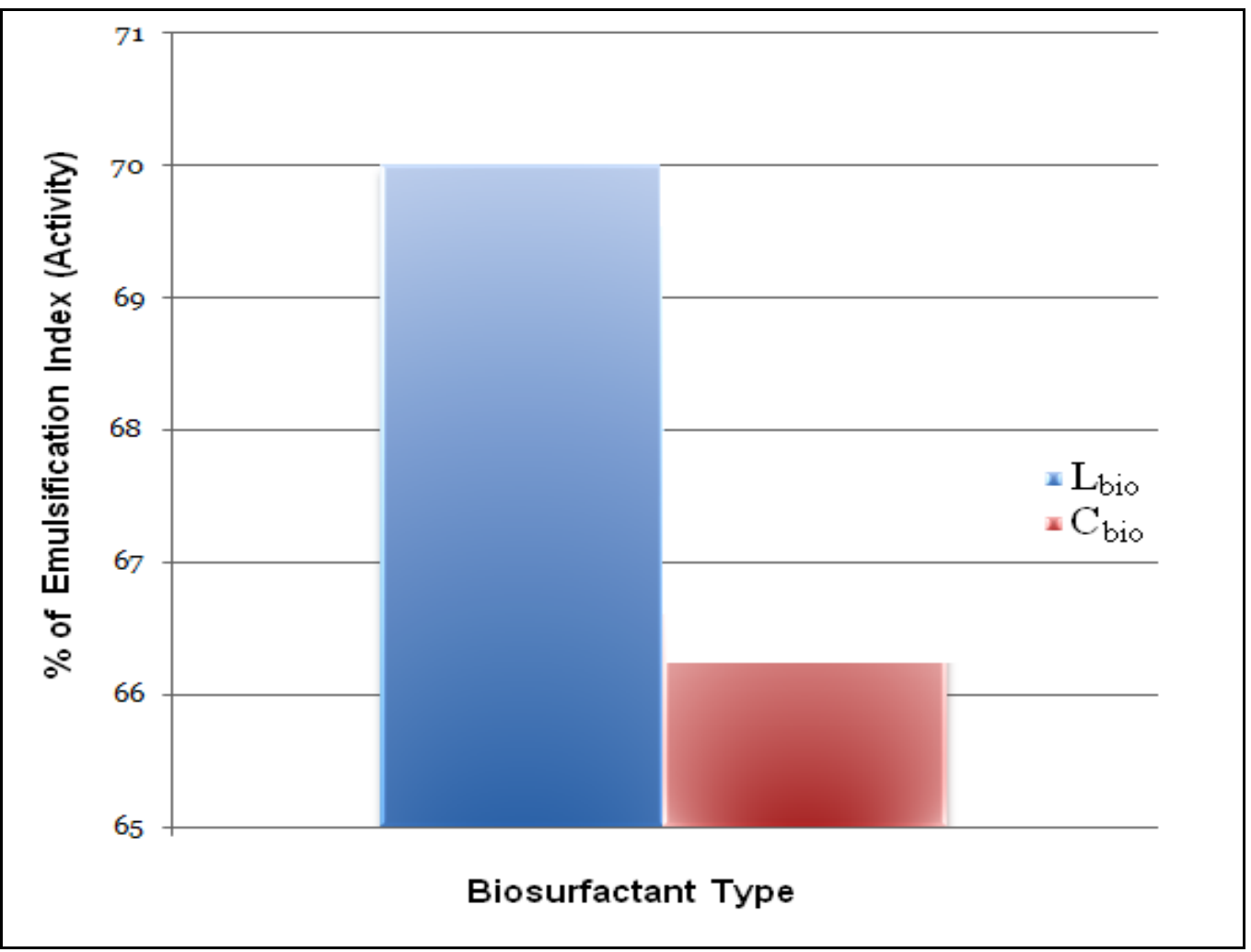

Figure (8): The activity of the biosurfactant after lhr, which indicated by its effect on Kerosene as the hydrophobic compound

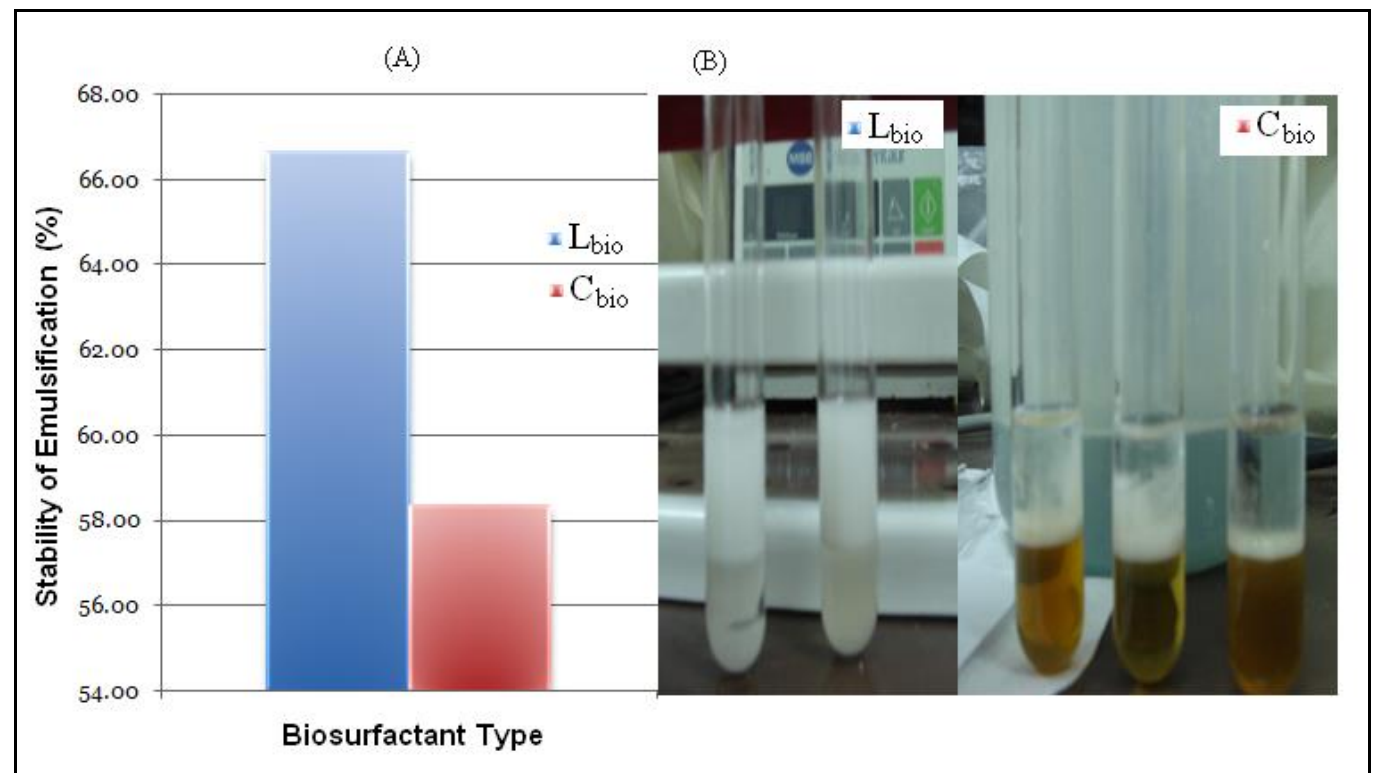

Figure (9): Comparison between commercial and laboratory produced biosurfactant on the basis of (A) stability of the biosurfactant after $24 \mathrm{hrs}$ and (B) Emulsification activity after $72 \mathrm{hrs,}$, which indicated by its effect on 
Kerosene as the hydrophobic compound. Biosurfactants $\left(\mathrm{L}_{\text {bio }}\right)$ had comparable emulsification activity and superior emulsification stability compared to the artificial surfactants tested $\left(C_{\text {bio }}\right)$

\section{CONCLUSIONS:}

The isolated microorganisms were characterized and identified as $P$. aeruginosa AJ746 135 using the 1 6S DNA PCR techniques and the sequencing was compared with database of GenBank. The isolates have shown optimum growth rate at substrate concentration $(\mathbf{1 \%})$ with specific growth rate and total protein of $0.659 \mathrm{~h}^{-1}$ and $170 \mu \mathrm{g} \mathrm{mL} \mathrm{m}^{-1}$ respectively. The concentration of biosurfactant fermentation was $114 \mathrm{mgL}^{-1}$. The emulsification index showed that the laboratory-produced biosurfactant was much more stable than the commercial biosurfactant. Our laboratory observation proved that $\mathbf{L}_{\text {bio }}$ was stable up to one month while the $C_{\text {bio }}$ was up to one week.

Further study is underway to study the effect of the laboratory-produced biosurfactant in washing and enhancing degradation of contaminated hydrocarbon soil and compare the results obtained with the commercial biosurfactant.

\section{REFERENCES:}

1-Karanth NGK, Deo PG, Veenanadig NK (1999): Microbial production of biosurfactants and their importance. Curr Sci. 77:116-126.

2-Costa SGVAO, Nitschke M, Haddad R, Eberlin M, Contiero J (2006): Production of Pseudomonas aeruginosa LBI rhamnolipids following growth on Brazilian native oils. Process Biochem. 41:483-488

3-Mulligan CN., Catherine N., (2005): Environmental application for biosurfactants. Environ Pollut 133:183-198 4-Volkering F., Breure A.M., Rulkens W.H. (1998): Microbiological aspects of surfactant use for biological soil remediation, Biodegradation. 8:401-417.

5-Mulligan C.N., Yong R.N., Gibbs B.F. (2001): Surfactant-enhanced remediation of contaminated soil: a review, Eng. Geol. 60: 371-380.

6-Falatko D.M., Novak J.T.(1992): Effect of biologically produced surfactants on the mobility and biodegradation of petroleum hydrocarbons, Water Environ. Res. 64 (2) 163-169.

7-Banat I.M., Makkar R.S., Cameotra S.S., (2000): Potential commercial applications of microbial surfactants, Appl. Microbiol. Biotechnol. 53: 495-508.

8-Anna L.M.S., Sebastian G.V., Pereira JR N., Alves T.L.M., Menezes E.P., Freire D.M.G.(2001): Production of Biosurfactant from a New and Promising Strain of Pseudomonas aeruginosa PA1, Applied Biochemistry and Biotechnology, 92: 459-467.

9-Desai, J.D. and Banat, I.M., (1997): Microbial Production of surfactants and their commercial potential. Microbiology and molecular biology reviews, Mar. p. 47-64.

10-Wei Y.H., Chou J.L., Chang J.S. (2005): Rhamnolipid production by an indigenous isolate Pseudomonas aeruginosa J4 originating from petrochemical wastewater, Biochem. Eng. J. 27 (2) 146-154.

11-Dai Kitamoto, Hiroko Isoda, Tadaatsu Nakahara, (2002): Functions and Potential Applications of Glycolipid Biosurfactants from Energy-Saving Materials to Gene Delivery Carriers. Journal of Bioscience and Bioengineering, 94: 187-201.

12-Kitamoto, D. (2001): New findings on glycolipid biosurfactants ranging from biologically active compounds to energysaving materials. Oleoscience, 1: 17-31 
13-Soberón-Chávez, G., Lépine, F. and Déziel, (2005): E. Production of rhamnolipids by Pseudomonas aeruginosa. Appl. Microbiol. Biotechn., 68: 718-725.

14-Dembitsky, V.M. (2004): Astonishing diversity of natural surfactants: 1 . Glycosides of fatty acids and alcohols. Lipids, 39: 933953.

15-Van Bogaert, I.N.A., Saerens, K., De Muynck, C., Develter, D., Soetaert, W. and Vandamme, (2007): E.J. Microbial production and application of sophorolipids. Appl. Microbiol. Biotechn., 76: 23-34.

16-Arutchelvi, J.I., Bhaduri, S., Uppara, P.V. and Doble, M. (2008): Mannosylerythritol lipids: a review. J. Ind. Microbiol. Biotechnol., $35,1559-1570$.

17-Gautam K.K. and Tyagi V.K. (2005): Microbial Surfactants: A Review. Journal of Oleo Science 55 (4): 155-166.

18-Malin Hultberg, Karl-Johan Bergstrand, Sammar Khalil and Beatrix Alsanius. (2008): Characterization of biosurfactant-producing strains of fluorescent pseudomonads in a soilless cultivation system. Journal of Antonie van Leeuwenhoek. 94: 329-334.

19-Maier R. M., Soberon Chavez G. (2000): Pseudomonas aeruginosa rhamnolipids: biosynthesis and potential applications. $J$ of Applied microbiology and biotechnology. 54:(5) 625-633.

20-Ochoa-Loza, F.J., J.F. Artiola, and R.M. Maier. (2001): Stability constants for the complexation of various metals with a rhamnolipid biosurfactant. Journal of Environmental Quality 30:479-485.

21-Neilson, J.W., Artiola J.F., and Maier R.M. (2003): Characterization of lead removal from contaminated soils by nontoxic soilwashing agents. Journal of Environmental Quality 32:899-908.
22-Stanghellini, M.E. and R.M. Maier (Miller). (1997): Biosurfactants: their identity and potential efficacy in the biological control of zoosporic plant pathogens. Plant Disease 81:4-12.

23-Liang-Ming Whang, Pao-Wen G. Liu, ChihChung Ma and Sheng-Shung Cheng. (2008): Application of rhamnolipid and surfactin for enhanced diesel biodegradation-Effects of pH and ammonium addition. Journal of Hazardous Materials. (Article in Press).

24-Marcia Nitschke, Siddhartha G. V. A. O. Costa, Renato Haddad, Lireny A. G. Gonçalves, Marcos N. Eberlin, Jonas Contiero. (2005): Oil Wastes as Unconventional Substrates for Rhamnolipid Biosurfactant Production by Pseudomonas aeruginosa LBI. Biotechnology Progress. 21(5): $1562-1566$.

25-Marcia Nitschke, Siddhartha G. V. A. O. Costa, Jonas Contiero. (2008): Rhamnolipid Surfactants: An Update on the General Aspects of These Remarkable Biomolecules. Biotechnology Progress. 21 (6): 1593 - 1600.

26-Wouter H. Noordman $\uparrow$ and Dick B. Janssen. (2002): Rhamnolipid Stimulates Uptake of Hydrophobic Compounds by Pseudomonas aeruginosa. 68(9): 4502-4508.

27-Anand S. Nayaka, M.H. Vijaykumara and T.B. Karegoudar. (2009): Characterization of biosurfactant produced by Pseudoxanthomonas sp. PNK-04 and its application in bioremediation. International Biodeterioration \& Biodegradation. 63 (1): 73-79.

28-Kosaric, N., (2001): Biosurfactants for Soil Bioremediation, Food Technol. Biotechnol., 39:295-304.

29-David Hendricks Bergey, John G. Holt (1994): 'Bergey's Manual of Determinative Bacteriology" Vol. 9, Lippincott Williams \& Wilkins, pp. 3-17. 
30-Andrew Macrae (2000): The Use of $16 \mathrm{~S}$ RDNA Methods in Soil Microbial Ecology. Brazilian Journal of Microbiology, 31:77-82.

31-The National Center for Biotechnology Information (NCBI) (2008): BLAST finds regions of similarity between biological sequences. www.ncbi.nlm.nih. gov/BLAST.

32-Lowry, O. H., Rosenbrough N. J., Randall R. J. (1951): Protein Measurement with the Folin Phenol Reagent. J. Biol. Chem., 193: 265-275.

33-Santa Anna, L.M., Sebastian, G.V., Menezes, E.P., Alves, T.L.M., Santos, AS., Pereira Jr., N. and Freire, D.M.G., (2002). Production of biosurfactants from Pseudomonas aeruginosa Pal isolated in oil environments, Brazilian Journal of Chemical Engineering, 19:159166.
34-David G. Cooper and Beena G. Goldenberg. (1987): Surface-Active Agents from Two Bacillus Species. Appl Environ Microbiol. 53(2): 224-229.

35-Dubois M., Gilles K. A., Hamilton J. K., Rebers P. A., Smith F., (1956): Colorimetric method for determination of sugars and related substances, Anal. Chem., 28: 350-356. 36-Anthony I Okoh, (2006): Biodegradation alternative in the cleanup of petroleum hydrocarbon pollutants. Biotechnology and Molecular Biology Review. 1 (2): 38-50.

37-Yeliz Asfçe, Macid Nurbasf, Yesfim Sag Açekel. (2008). Removal of zinc ions from a soil component Na-feldspar by a rhamnolipid biosurfactant. 223: 361-365. 